Hirotaka Yoshioka • Yasuaki Shirayoshi Mitsuo Oshimura

\title{
A novel in vitro system for analyzing parental allele-specific histone acetylation in genomic imprinting
}

\begin{abstract}
One of the obstacles in studying human genomic imprinting is distinguishing the parental origin of alleles in diploid cells. To solve this problem, we have constructed a library of mouse A9 hybrids in which individual clones contain a single human chromosome of known parental origin. Here we extend this in vitro system to the analysis of the role of histone acetylation in the allelic expression of human imprinted genes. The levels of histone $\mathrm{H} 4$ acetylation of the imprinted human LIT1, H19, and SNRPN genes were examined by a chromatin immunoprecipitation (ChIP) assay in mouse A9 hybrids with a single human chromosome of known parental origin. We demonstrated that $\mathrm{H} 4$ histones associated with the actively expressed alleles of imprinted LIT1, H19, and SNRPN genes were highly acetylated, whereas they were hypoacetylated in the silent alleles. Furthermore, treatment of A9 hybrids with trichostatin A (TSA), an inhibitor of histone deacetylase, resulted in transcriptional reactivation of the silent alleles for LIT1 and $S N R P N$, suggesting that histone deacetylation is one of the key regulatory mechanisms in genomic imprinting. These results indicate that our monochromosomal hybrid system is a new technology for analyzing histone modifications between parental alleles in human imprinted genes.
\end{abstract}

Key words Genomic imprinting · Monochromosomal hybrid cells . DNA methylation - Histone acetylation . Trichostatin A - Chromatin immunoprecipitation assay

H. Yoshioka · Y. Shirayoshi $\cdot$ M. Oshimura $(\square)$ Core Research for Evolutional Science and Technology (CREST) project, Department of Molecular and Cell Genetics, School of Life Sciences, Faculty of Medicine, Tottori University, 86 Nishimachi, Yonago, Tottori 683-8503, Japan

Tel. +81-859-34-8260; Fax +81-859-34-8134

e-mail: oshimura@grape.med.tottori-u.ac.jp

\section{Introduction}

Genomic imprinting is thought to result from differential epigenetic modifications of alleles of different parental origin that lead to parent-of-origin-specific expression (Reik and Walter 2001). Causative mechanisms of genomic imprinting such as cytosine methylation in $\mathrm{CpG}$ dinucleotides (Li et al. 1992), chromatin structure (Feil and Kelsey 1997), and replication timing (Simon et al. 1999) have become clear in studies of many human and mouse imprinted genes. The in vivo mutational studies of related DNA methyltransferase genes revealed that cytosine methylation in $\mathrm{CpG}$ dinucleotides has a great influence on the maintenance of parental allele-specific expression of imprinted genes and on mammalian development ( $\mathrm{Li}$ et al. 1992; Okano et al. 1999). Recently, it has been demonstrated that the methyl cytosine binding protein $\mathrm{MeCP} 2$ binds the corepressor of $\mathrm{mSin} 3 \mathrm{~A}$, which constitutes the core multiprotein complex including histone deacetylases HDAC1 and HDAC2 (Jones et al. 1998; Nan et al. 1998), and that DNA methyltransferase Dnmt1 is itself associated with histone deacetylase activity (Fuks et al. 2000). Furthermore, epigenetic gene regulation is accomplished through the modulation of chromatin packaging that results in several forms of posttranscriptional modification of histones (Wolffe and Matzke 1999). Thus, the process of DNA methylation may generate an altered chromatin state via histone deacetylase activity for allele-specific epigenetic modification in genomic imprinting.

The presence of both paternal and maternal genomes in diploid cells is a significant barrier to the analysis of the mechanisms of genomic imprinting, including histone modification. Genetic polymorphisms in over $160 \mathrm{bp}$ DNA wrapped around an octamer of the four core histones are required for analyzing the parent-of-origin-specific histone modifications of each nucleosome in diploid cells. However, the analysis of critical nucleosomes for epigenetic regulation could be hampered by rare incidences of nucleotide sequence variations. Indeed, the analysis of allele-specific histone acetylation of imprinted genes has been limited to 
regions of the genome exhibiting polymorphism, as shown in Pedone et al. (1999). We have constructed a library of mouse A9 hybrids containing single human paternal or maternal chromosomes via microcell-mediated chromosome transfer (Kugoh et al. 1999). The parent-of-originspecific expression and DNA methylation of human imprinted genes, such as H19, SNRPN, and $I P W$, were maintained faithfully (Meguro et al. 1997; Mitsuya et al. 1998) as was the replication timing of $H 19$ (unpublished data) in these A9 hybrids.

In this article, we have applied our monochromosomal hybrid system to the analysis of the relative levels of histone acetylation in human imprinted genes. To gain insight into the potential significance of histone acetylation in the regulation of genomic imprinting, the relative levels of allelespecific histone $\mathrm{H} 4$ acetylation were investigated by using a chromatin immunoprecipitation (ChIP) assay with antibodies against acetylated histone $\mathrm{H} 4$ (Crane-Robinson et al. 1999). In addition, the expression profiles of several imprinted genes were compared in trichostatin A (TSA)treated and untreated A9 hybrids. We demonstrate here that differential acetylation of histone $\mathrm{H} 4$ between parental alleles is associated with the epigenetic regulation of some imprinted genes. Thus, this monochromosomal hybrid system enables efficient analysis for demonstrating differences in histone modification patterns between alleles of maternal and paternal origin.

\section{Materials and methods}

\section{Cell culture and TSA treatment}

Mouse A9 cells were cultured in Dulbecco's modified Eagle's medium (DMEM) (Sigma, St. Louis, MO, USA), plus $10 \%$ bovine calf serum at $37^{\circ} \mathrm{C}, 5 \% \mathrm{CO}_{2}$. Mouse A9 hybrids containing a single human chromosome, either 11 or 15, of known parental origin (Kugoh et al. 1999), were cultured under the same conditions as A9 cells with $3 \mu \mathrm{g} / \mathrm{ml}$ blasticidin S hydrochloride (Invitrogen, Groningen, The Netherlands). Normal human fibroblasts were obtained with standard punch biopsies from a normal adult and cultured in DMEM supplemented with $10 \%$ fetal bovine serum at $37^{\circ} \mathrm{C}, 5 \% \mathrm{CO}_{2}$.

For TSA treatment, human fibroblasts, mouse A9 cells, and mouse A9 hybrids were plated at a density of $5 \times 10^{6}$ cells/dish with $100 \mathrm{ng} / \mathrm{ml}$ of TSA (Wako Pure Chemicals, Osaka, Japan). After 24 hours, all the cells were harvested for reverse transcriptase-polymerase chain reaction (RTPCR) analysis.

\section{Chromatin immunoprecipitation assay}

For chromatin preparation, $10^{8}$ cells were washed with icecold phosphate-buffered solution (PBS) in the presence of protease inhibitors $[1 \mathrm{mM}$ phenylmethylsulfonyl fluoride (PMSF), $1 \mu \mathrm{g} / \mathrm{ml}$ aprotinin, $1 \mu \mathrm{g} / \mathrm{ml}$ pepstatin] (Roche
Diagnostics, Indianapolis, IN, USA), and resuspended in $\mathrm{N} 1$ buffer $[15 \mathrm{mM}$ Tris- $\mathrm{HCl} \mathrm{pH} 7.6,60 \mathrm{mM} \mathrm{KCl}, 15 \mathrm{mM}$ $\mathrm{NaCl}, 5 \mathrm{mM} \mathrm{MgCl}, 0.1 \mathrm{mM}$ ethyleneglycoltetraacetic acid (EGTA) $\mathrm{pH} 7.8,0.3 \mathrm{M}$ sucrose, $0.5 \mathrm{mM}$ dithiothreitol (DTT), $0.1 \mathrm{mM}$ PMSF, $5 \mathrm{mM}$ sodium butyrate]. After permeabilization with addition of Nonidet P-40, nuclei were recovered by ultracentrifugation through an $\mathrm{N} 2$ buffer cushion $(15 \mathrm{mM}$ Tris- $\mathrm{HCl} \mathrm{pH} 7.6,60 \mathrm{mM} \mathrm{KCl}, 15 \mathrm{mM} \mathrm{NaCl}$, $5 \mathrm{mM} \mathrm{MgCl}, 0.1 \mathrm{mM}$ EGTA pH $7.8,1.5 \mathrm{M}$ sucrose, $0.5 \mathrm{mM}$ DTT, $0.1 \mathrm{mM}$ PMSF, $5 \mathrm{mM}$ sodium butyrate). The nuclear pellets were then resuspended in micrococcal nuclease (MNase) buffer $(20 \mathrm{mM}$ Tris- $\mathrm{HCl} \mathrm{pH} 8.0,5 \mathrm{mM} \mathrm{NaCl}$, $2.5 \mathrm{mM} \mathrm{CaCl}_{2}$ ) and digested with 100 units of MNase (Takara, Kyoto, Japan) at $37^{\circ} \mathrm{C}$ for $10 \mathrm{~min}$ to isolate the mononucleosomes and the smaller oligonucleosomes. The MNase reaction was stopped by adding a final concentration of $5 \mathrm{mM}$ ethylenediaminetetraacetate $\mathrm{pH}$ 8.0. Mononucleosome and the smaller oligonucleosome preparations were subjected to immunoprecipitation with antibodies against acetyl histone $\mathrm{H} 4$ using an AcetylHistone H4 Immunoprecipitation Assay Kit (Upstate Biotechnology, Lake Placid, NY, USA) according to the manufacturer's instructions with minor modifications.

Multiplex PCR analysis of chromatin immunoprecipitated DNA

Immunoprecipitated DNA was analyzed using the following primers and PCR conditions. The human-specific PCR primers for imprinted genes used were LIT1-F: 5'-GTTG CTGAGGTGAGCTGTGT-3' and LIT1-R: 5' -TGTCCAT AAGGTGCAGATGG-3' for LIT1; H19-1F: 5'-TTCTGG GAATAGGACGCTCA-3' and H19-1R: 5'-CCAGGCCA TGACACTGAAG-3', H19-2F: 5'-CGGTCTTCAGACA GGAAAGTG-3' and H19-2R: 5'-ATCCAGTTGACCGA GCTTGT-3' for H19; and SNT5.9-F: 5' -CAGGCTTCGCA CACATCC-3' and SNT5.9-R: 5'-CAGGTCATTCCGG TGAGG-3' for $S N R P N$. The mouse G6pd promoter was amplified by multiplex PCR as an internal control in the same reaction tube with each imprinted gene using the PCR primers G6pd-F: 5'-ATTTTCAAGGCACCGCATC-3' and G6pd-R: 5'-CTAGTTTGGCTTCGGAGCTG-3'. The PCR conditions were 31 cycles of 94,62 , and $72^{\circ} \mathrm{C}$ for 30 , 30 , and 30 s, respectively, for $L I T 1$ and $S N R P N$, and 31 cycles of 94,60 , and $72^{\circ} \mathrm{C}$ for 30,30 , and 30 s, respectively, for H19. PCR products were quantified with the fluorescent image-analyzing system FMBIOII Multi-View (Takara) to normalize for G6pd products and electrophoresed on $12 \%$ polyacrylamide gel, followed by ethidium bromide staining.

\section{Expression analysis by RT-PCR}

Total RNA was extracted using the RNeasy mini kit (Qiagen, Hilden, Germany) and treated with DNase I (Roche Diagnostics) to remove any DNA contamination. First-strand cDNA synthesis was carried out with $(+)$ or without (-) M-MLV reverse transcriptase (Gibco BRL, 
Rockville, MD, USA) using an oligo $(\mathrm{dT})_{15}$ primer (Roche Diagnostics).

The expression of human imprinted genes was detected by using the human-specific primers Lit102: 5'-TCTGGT TCATGTCACTCTGTGGAGCAG-3' and Lit202: 5'CTCCCAAAAGCAGAGTTTTGGCAATAT-3' for LIT1 (Mitsuya et al. 1999); H1: 5'-TACAACCACTGCA CTACCTG-3' and H3: 5'-TGGAATGCTTGAAGGCT GCT-3' for H19 (Rainier et al. 1993); and S4: 5' -CTACTC TTTGAAGCTTCTGCC-3' and AS4: 5'-TGAAGATTCG GCCATCTTGC-3' for $S N R P N$. To detect the expression of LIT1, we used a step-down PCR protocol. Nine rounds of PCR were carried out as follows, with the annealing temperature being reduced by $2^{\circ} \mathrm{C}$ every three cycles: $95^{\circ} \mathrm{C}$ for $30 \mathrm{~s}, 62^{\circ} \mathrm{C}$ for $30 \mathrm{~s}$, and $72^{\circ} \mathrm{C}$ for $30 \mathrm{~s}$. Thirty-five subsequent rounds of PCR were carried out as follows: $95^{\circ} \mathrm{C}$ for $30 \mathrm{~s}, 56^{\circ} \mathrm{C}$ for $30 \mathrm{~s}$, and $72^{\circ} \mathrm{C}$ for $30 \mathrm{~s}$. The other PCR conditions were 35 cycles of $94^{\circ} \mathrm{C}$ for $45 \mathrm{~s}, 62^{\circ} \mathrm{C}$ for $30 \mathrm{~s}$, and $72^{\circ} \mathrm{C}$ for $90 \mathrm{~s}$ for $S N R P N$ and 34 cycles of $94^{\circ} \mathrm{C}$ for $1 \mathrm{~min}, 62^{\circ} \mathrm{C}$ for $3 \mathrm{~min}$, and $72^{\circ} \mathrm{C}$ for $5 \mathrm{~min}$ for $\mathrm{H} 19$.

\section{Results}

Histone $\mathrm{H} 4$ acetylation of imprinted genes

To examine the role of histone acetylation in genomic imprinting, we used a series of mouse A9 hybrid cells containing a single human paternal or maternal chromosome as a source for chromatin preparation. The imprinted human genes, LIT1 and H19 on chromosome 11 and SNRPN on chromosome 15, were selected for analysis of allelic histone $\mathrm{H} 4$ acetylation using the ChIP assay (Crane-Robinson et al. 1999). In the A9 hybrids, the epigenetic status of the transferred human chromosome is maintained faithfully; for example, the expression pattern is dependent on the parental origin and the DNA methylation status (Meguro et al. 1997; Mitsuya et al. 1998, 1999; Kugoh et al. 1999).

Chromatin was prepared from A9 hybrids and immunoprecipitated with antibodies raised against acetylated histone H4. In immunoprecipitated nucleosomes (bound fraction), DNA fragments containing the sequences described below were amplified by multiplex PCR with primers for a positive control gene, in this case $G 6 p d$, which allowed for a semi-quantitative assay of association of a particular DNA sequence with acetylated histones. Amplification of DNA was compared between A9 hybrids containing either human paternal chromosome (paternal A9 hybrids) or the corresponding maternal chromosome (maternal A9 hybrids).

We first analyzed histone $\mathrm{H} 4$ acetylation in a region spanning the maternally methylated $\mathrm{CpG}$ island of LIT1, which overlapped with two clusters of short direct repeat sequences (Fig. 1A). PCR primers for LIT1 were chosen from a region between the two direct repeat clusters because of the difficulty with generating primers to the repeat regions. Equal amounts of DNA from input, unbound, and bound nucleosomes, which were based on G6pd amplifica- tion, were amplified and compared between the paternal and maternal A9 hybrids. The input and unbound fractions gave bands of approximately equal intensity, irrespective of their parental origin (data not shown). However, only the LIT1 alleles from two independent paternal A9 hybrids, A9(11P)-1 and A9(11P)-2, were amplified in the bound fraction (Fig. 1B). Virtually, no amplification was observed for the LIT1 alleles from the maternal A9 hybrids, A9(11M)-1 and A9(11M)-2. Therefore, in the bound fraction a marked difference exists in the relative amplification level of LIT1 alleles in the two parental A9 hybrids.

To investigate the histone $\mathrm{H} 4$ acetylation status of the $H 19$ gene, we first analyzed the paternally methylated $\mathrm{CpG}$ island in the $5^{\prime}$ cis-regulatory element (Fig. 1A, H19-1), which has potential insulator activity (Bell and Felsenfeld 2000; Hark et al. 2000). Using the same amounts of immunoprecipitated nucleosomes, the $H 19$ alleles in maternal hybrids were amplified strongly (Fig. 1C, H19-1). On the other hand, the paternal $\mathrm{H} 19$ alleles were amplified poorly compared with the maternal alleles. Although less evident, similar results were obtained by PCR amplification using different primers for $\mathrm{H} 19$ alleles corresponding to the $\mathrm{CpG}$ island of the promoter region (Fig. 1C, H19-2) (Dugimont et al. 1998). Therefore, the maternal $H 19$ allele, the transcriptionally active allele, is suggested to be more acetylated than the paternal allele.

Because the LIT1 and H19 genes are located on chromosome 11p15.5, we next analyzed the chromatin acetylation status of the SNRPN gene using A9 hybrids containing human chromosome 15 . The maternally methylated $\mathrm{CpG}$ island surrounding exon 1 of the SNRPN gene is indispensable for the establishment of the paternal imprint in the male germ line (Fig. 2A) (Bielinska et al. 2000). Therefore, we chose PCR primers for $S N R P N$ alleles from this region. As with the LIT1 gene, only the active paternal alleles were heavily immunoprecipitated by anti-acetylated histone $\mathrm{H} 4$ antibodies, indicating that a clear difference exists in the acetylation status between the paternal and maternal A9 hybrids (Fig. 2B).

Effect of inhibition of histone deacetylase

Inhibition of histone deacetylase with TSA increases the acetylation level of histones (Yoshida et al. 1990) and activates gene transcription in some cases (Kouzarides 1999). To test the relevance of histone acetylation to the relative transcriptional activity of the paternal and maternal alleles of imprinted genes, we analyzed the effects of TSA on the expression status of $L I T 1, H 19$, and $S N R P N$ in A9 hybrids. RT-PCR analysis showed that untreated A9 hybrids maintained the imprinting of the LIT1, SNRPN, and H19 genes, which was exclusive paternal, paternal, and maternal expression, respectively (Fig. 3). Treatment of the A9 hybrids with $100 \mathrm{ng} / \mathrm{ml}$ of TSA altered the expression of the LIT1 and $S N R P N$ genes, since TSA reactivated the normally silent $L I T 1$ and $S N R P N$ genes with a maternal origin (Fig. $3 \mathrm{~A}$ and $3 \mathrm{~B}$ ). These results suggest that histone acetylation plays a crucial role in maintaining allele-specific expression 


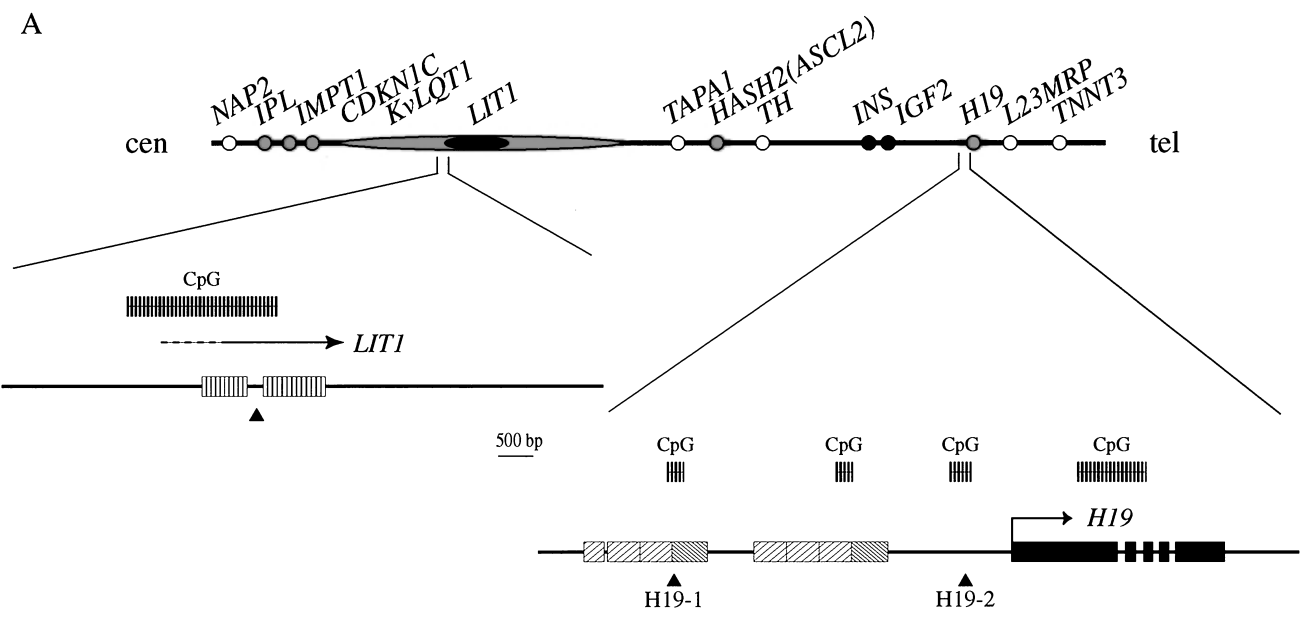

B

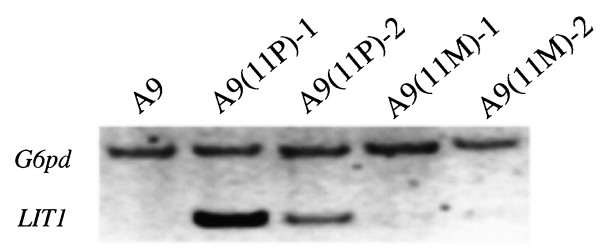

C

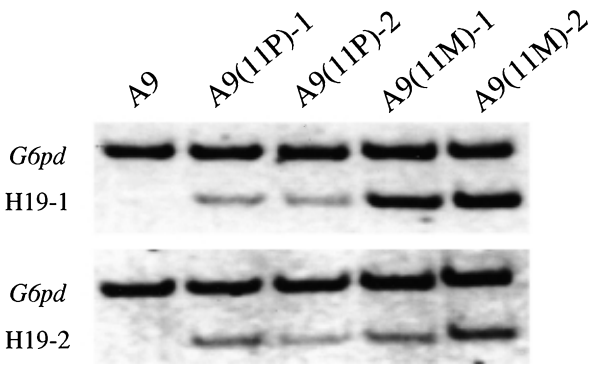

Fig. 1. A-C. Chromatin immunoprecipitation assay of the imprinted LIT1 and H19 genes on human chromosome 11p15.5. A Overview of the imprinted domain on human chromosome 11p15.5. Black, gray, and white circles indicate paternally expressed imprinted genes, maternally expressed imprinted genes, and nonimprinted genes, respectively. In the lower left panel, the structure of the differential methylated $C p G$ island of LIT1 is shown. This region is characterized by two clusters of short direct repeat sequences (striped boxes). We analyzed the relative levels of histone $\mathrm{H} 4$ acetylation in a region between these two direct repeat clusters (arrowhead). The LIT1 transcriptional start site has not been determined clearly, as indicated by the dotted line and arrow. In the lower right panel, the structure of the upstream differential methylated $C p G$ islands of $H 19$ is shown. Two types of $400 \mathrm{bp}$ repeat sequences (hatched boxes) are indicated. Two regions indicated with arrowheads, H19-1 and H19-2, were analyzed by a chromatin immuno precipitation assay. The black boxes and the arrow indicate the exons and transcriptional start site, respectively. B, C Multiplex polymerase chain reaction (PCR) analysis of DNA in chromatin immunoprecipitated with anti-acetyl-H4 antibodies from mouse A9 recipient cells and mouse A9 hybrids with paternal chromosome 11 A9 $(11 P)$ clones, and with maternal chromosome $11 A 9(11 M)$ clones. DNA from antibodybound chromatin fractions was amplified by multiplex PCR using primer pairs for G6pd (top band) and each imprinted gene (bottom band), LIT1 (B) and H19 (C) of LIT1 and SNRPN. In contrast, the same TSA treatment in mouse A9 hybrids did not alter the exclusive maternal expression status of $H 19$, indicating that restoring acetylation of histones was insufficient to reactivate $H 19$ (Fig. 3C). Thus, there seems to be at least two types of regulatory systems leading to the silencing of one allele of imprinted genes.

\section{Discussion}

In this study, we introduced a new method for studying the histone modifications in imprinted genes using a monochromosomal hybrid system (Kugoh et al. 1999). This method is based on the fact that the epigenetic status of human imprinted genes is maintained faithfully in A9 hybrids containing a single human chromosome. Since polymorphisms are not required to distinguish parental alleles in our system, the monochromosomal A9 hybrids enable us to examine the chromatin structure throughout the genomic regions of the imprinted genes.

Using A9 hybrids with human chromosome 11, we found that the silent and hypermethylated LIT1 and H19 alleles were hypoacetylated, although LIT1 and H19 belong to different imprinted subdomains of human chromosome 11p15.5 (Lee et al. 1999; Mitsuya et al. 1999; Horike et al. 2000). Conversely, histones of the expressed and undermethylated LIT1 and H19 alleles were hyperacetylated. In the case of H19, the status of histone acetylation was likely to be maintained throughout the $5^{\prime}$ cis-regulatory element because the $\mathrm{CpG}$ island of the H19 promoter showed the same allelic histone acetylation as the upstream $\mathrm{CpG}$ island. The same relationship between acetylation and methylation was observed in imprinted SNRPN alleles using different A9 hybrids containing human chromosome 15 . This finding confirmed recent reports that the two alleles of SNRPN displayed different levels of histone acetylation (Saitoh and Wada 2000; FulmerSmentek and Francke 2001), validating the value of human 
Fig. 2. A, B. Chromatin immunoprecipitation assay of the imprinted $S N R P N$ gene on human chromosome 15q11-q13. A Overview of the imprinted domain on human chromosome $15 \mathrm{q} 11-\mathrm{q} 13$ and the structure of the upstream region of the SNRPN locus. Black boxes represent exons and the arrow indicates transcription from exon 1 . B Multiplex PCR analysis of DNA in chromatin immunoprecipitated with anti-acetyl-H4 antibodies from mouse A9 recipient cells and mouse $\mathrm{A} 9$ hybrids with paternal chromosome $15 A 9(15 P)$ clones and with maternal chromosome $15 A 9(15 M)$ clones. DNA from antibodybound chromatin fractions was amplified by multiplex PCR using primer pairs for G6pd (top band) and SNRPN (bottom band)
A

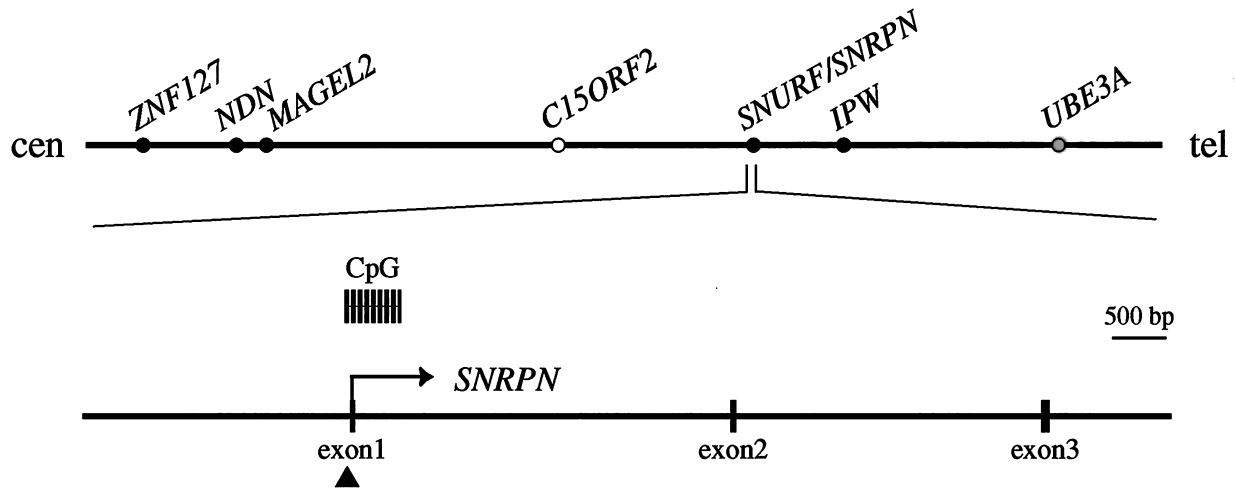

B

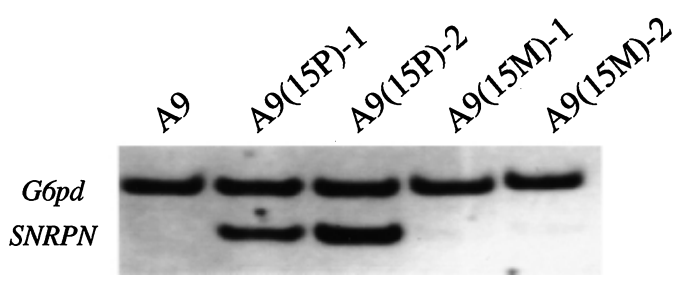

monochromosomal hybrids as a resource for the efficient analysis of histone modifications. In contrast to our focus on the differentially methylated regions (DMR) of imprinted genes, previous reports were limited to regions that exhibit polymorphisms. It is well known that DMR play an essential role in the regulation of various imprinted genes and contain important cis-regulatory elements. We examined the CpG islands of LIT1, H19, and SNRPN, which have been demonstrated to be indispensable for imprinted expression of each gene (Huq et al. 1997; Dao et al. 1999; Horike et al. 2000), and found that histone modification of these regions was involved in allelic expression of imprinted genes. Thus, we can directly study the role of chromatin modifications around essential cis-regulatory elements responsible for the regulation of imprinting using our system.

We also examined the effect of TSA on the expression profiles of imprinted genes. In the A9 hybrids, TSA treatment reactivated the silent allele of the LIT1 and SNRPN genes. Therefore, histone acetylation modulates not only the allelic chromatin modification of differentially methylated $\mathrm{CpG}$ islands but also the allelic expression of LIT1 and SNRPN. Since methylated $\mathrm{CpG}$ islands recruit the mSin3A-histone deacetylase complex (Jones et al. 1998; Nan et al. 1998), we hypothesize that recruitment of this complex to the methylated $\mathrm{CpG}$ island on the maternal allele of LIT1 and SNRPN causes repression through histone deacetylation accompanied by chromatin modification. On the other hand, we found that TSA treatment had no effect on the imprinted expression of the $H 19$ gene in our A9 hybrids. This finding is compatible with previous work by Pedone et al. (1999), who showed that a combination of reagents that inhibit both DNA methylation and histone deacetylation was required to activate the imprinted $\mathrm{H} 19$ allele. A similar observation was made in the analysis of the corresponding region of the distal portion of chromosome 7 using methyltransferase-hypomorphic mice. This study showed that the H19 imprint was erased fully, but the allelic bias at Ipl, Impt1, $p 57^{k i p 2}$, and, to a lesser extent, Kvlqt1 persisted in the region surrounding Lit1 (Dao et al. 1999). The imprinted subdomain containing H19 is subjected to particular methylation-hyperdependent mechanisms, which is in contrast to the other imprinted subdomain of 11p15.5 including LIT1. Actually, the imprinted expression of $H 19$ is regulated by the methylation-dependent binding of zing finger protein CTCF to an insulator region (Bell and Felsenfeld 2000; Hark et al. 2000).

The organization of chromatin structures influences chromosome function and epigenetic gene regulation. The growing appreciation of chromatin has led to the "histone code" hypothesis, in which modifications of histones constitute a boundary element for interaction with critical proteins to elicit the appropriate chromatin-based processes (Strahl and Allis 2000). Given that genomic imprinting is parent-of-origin-specific epigenetic gene regulation, the analysis of histone modifications that can distinguish the two parental alleles is essential. Although we applied a chromatin immunoprecipitation assay to analyze histone modifications, this technique also is useful to address questions concerning the in vivo regulation of the interactions between cis-regulatory elements and trans-acting factors in the context of chromosome structure and nuclear organization (Orlando 2000). Ren et al. (2000) showed that DNA 
A

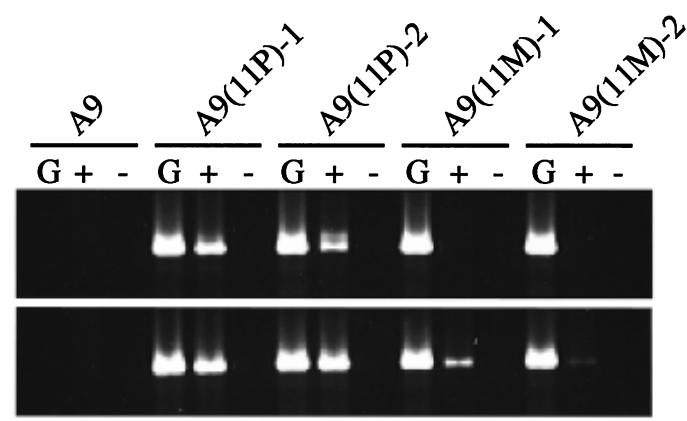

B
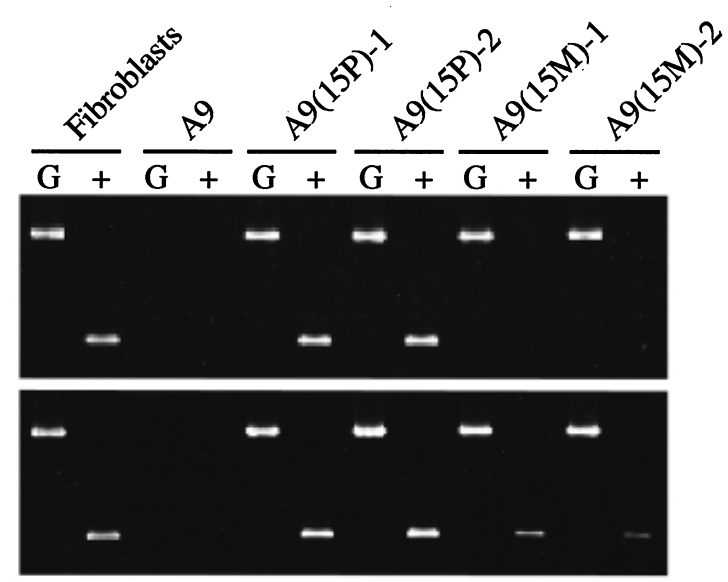

C

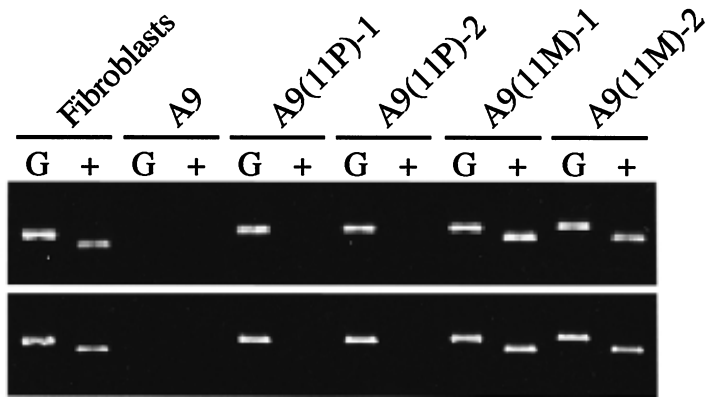

Fig. 3. A-C. Effect of histone deacetylase inhibitor. Expression profiles of imprinted genes, LIT1 (A), SNRPN (B) and H19 (C) were assessed by reverse transcriptase (RT)-PCR $(+)$ in trichostatin Auntreated (upper panels) and -treated (lower panels) human fibroblasts, mouse A9 recipient cells, and A9 hybrid clones, each containing a paternal allele, $A 9(11 P)$ or $A 9(15 P)$, or maternal allele, $A 9(11 M)$ or $A 9(15 M)$. Genomic PCR was performed to verify the existence of the human chromosome in mouse A9 hybrids $(\mathrm{G})$. RT-PCR products were not detected in reverse transcriptase-negative lanes (minus sign). Synthesis of first-strand cDNA was verified by PCR of Gapdh (data not shown)

fragments cross-linked to Gal4 or Ste12 were immunoprecipitated by specific antibodies, and the location of these DNA fragments were analyzed by DNA microarray. These genome-wide location analyses with expression profiles revealed how multiple functional pathways are coordinately controlled in vivo. In future applications, a differential display of the genome-wide location of DNA binding proteins between paternal and maternal A9 hybrids will facilitate investigation of gene regulatory networks and gene function in genomic imprinting. Thus, using these systems, we plan to clarify the regulation of imprinted genes.

Acknowledgments We would like to thank Drs. K. Mitsuya and M. Meguro (Tottori University) for their valuable suggestions, Drs. I. Horikawa (National Cancer Institute) and H. Komoda (Saga Medical School) for technical advice regarding TSA treatment and preparation of nuclei, respectively, and Dr. A. Kurimasa (Tottori University) for critical reading and comments on this manuscript. This work was supported by CREST of Japan Science and Technology Corporation (JST), a Grant-in-Aid for the Second Comprehensive 10-year Strategy for Cancer Control from the Ministry of Health and Welfare of Japan, a Grant-in-Aid for Scientific Research from the Ministry of Education, Science, Sports and Culture of Japan, and a grant from the Human Frontier Science Program Organization (HFSPO).

\section{References}

Bell AC, Felsenfeld G (2000) Methylation of a CTCF-dependent boundary controls imprinted expression of the Igf2 gene. Nature 405:482-485

Bielinska B, Blaydes SM, Buiting K, Yang T, Krajewska-Walasek M, Horsthemke B, Brannan CI (2000) De novo deletions of SNRPN exon 1 in early human and mouse embryos result in a paternal to maternal imprint switch. Nat Genet 25:74-78

Crane-Robinson C, Myers FA, Hebbes TR, Clayton AL, Thorne AW (1999) Chromatin immunoprecipitation assays in acetylation mapping of higher eukaryotes. Methods Enzymol 304:533-547

Dao D, Walsh CP, Yuan L, Gorelov D, Feng L, Hensle T, Nisen P, Yamashiro DJ, Bestor TH, Tycko B (1999) Multipoint analysis of human chromosome 11p15/mouse distal chromosome 7: inclusion of $H 19 / I G F 2$ in the minimal WT2 region, gene specificity of $H 19$ silencing in Wilms' tumorigenesis and methylation hyper-dependence of H19 imprinting. Hum Mol Genet 8:1337-1352

Dugimont T, Montpellier C, Adriaenssens E, Lottin S, Dumont L, Iotsova V, Lagrou C, Stehelin D, Coll J, Curgy JJ (1998) The H19 TATA-less promoter is efficiently repressed by wild-type tumor suppressor gene product p53. Oncogene 16:2395-2401

Feil R, Kelsey G (1997) Genomic imprinting: a chromatin connection. Am J Hum Genet 61:1213-1219

Fuks F, Burgers WA, Brehm A, Hughes-Davies L, Kouzarides T (2000) DNA methyltransferase Dnmt1 associates with histone deacetylase activity. Nat Genet 24:88-91

Fulmer-Smentek SB, Francke U (2001) Association of acetylated histones with paternally expressed genes in the Prader-Willi deletion region. Hum Mol Genet 10:645-652

Hark AT, Schoenherr CJ, Katz DJ, Ingram RS, Levorse JM, Tilghman SM (2000) CTCF mediates methylation-sensitive enhancer-blocking activity at the H19/Igf2 locus. Nature 405:486-489

Horike S, Mitsuya K, Meguro M, Kotobuki N, Kashiwagi A, Notsu T, Schulz TC, Shirayoshi Y, Oshimura M (2000) Targeted disruption of the human LIT1 locus defines a putative imprinting control element playing an essential role in Beckwith-Wiedemann syndrome. Hum Mol Genet 9:2075-2083

Huq AHMM, Sutcliffe JS, Nakao M, Shen Y, Gibbs RA, Beaudet AL (1997) Sequencing and functional analysis of the $S N R P N$ promoter: in vitro methylation abolishes promoter activity. Genome Res 7:642648

Jones PL, Veenstra GJC, Wade PA, Vermaak D, Kass SU, Landsberger N, Strouboulis J, Wolffe AP (1998) Methylated DNA and $\mathrm{MeCP} 2$ recruit histone deacetylase to repress transcription. Nat Genet 19:187-191

Kouzarides T (1999) Histone acetylases and deacetylases in cell proliferation. Curr Opin Genet Dev 9:40-48 
Kugoh H, Mitsuya K, Meguro M, Shigenami K, Schulz TC, Oshimura M (1999) Mouse A9 cells containing single human chromosomes for analysis of genomic imprinting. DNA Res 6:165-172

Lee MP, DeBaun MR, Mitsuya K, Galonek HL, Brandenburg S, Oshimura M, Feinberg AP (1999) Loss of imprinting of a paternally expressed transcript, with antisense orientation to $K V L Q T 1$, occurs frequently in Beckwith-Wiedemann syndrome and is independent of insulin-like growth factor II imprinting. Proc Natl Acad Sci U S A 96:5203-5208

Li E, Bestor TH, Jaenisch R (1992) Targeted mutation of the DNA methyltransferase gene results in embryonic lethality. Cell 69:915926

Meguro M, Mitsuya K, Sui H, Shigenami K, Kugoh H, Nakao M, Oshimura M (1997) Evidence for uniparental, paternal expression of the human $\mathrm{GABA}_{\mathrm{A}}$ receptor subunit genes, using microcell-mediated chromosome transfer. Hum Mol Genet 6:2127-2133

Mitsuya K, Meguro M, Sui H, Schulz TC, Kugoh H, Hamada H, Oshimura M (1998) Epigenetic reprogramming of the human H19 gene in mouse embryonic cells does not erase the primary parental imprint. Genes Cells 3:245-255

Mitsuya K, Meguro M, Lee MP, Katoh M, Schulz TC, Kugoh H, Yoshida MA, Niikawa N, Feinberg AP, Oshimura M (1999) LIT1, an imprinted antisense RNA in the human KvLQT1 locus identified by screening for differentially expressed transcripts using monochromosomal hybrids. Hum Mol Genet 8:1209-1217

Nan X, Ng HH, Johnson CA, Laherty CD, Turner BM, Eisenman RN, Bird A (1998) Transcriptional repression by the methyl-CpGbinding protein $\mathrm{MeCP} 2$ involves a histone deacetylase complex. Nature 393:386-389

Okano M, Bell DW, Haber DA, Li E (1999) DNA methyltransferases Dnmt3a and Dnmt3b are essential for de novo methylation and mammalian development. Cell 99:247-257
Orlando V (2000) Mapping chromosomal proteins in vivo by formaldehyde-crosslinked-chromatin immunoprecipitation. Trends Biochem Sci 25:99-104

Pedone PV, Pikaart MJ, Cerrato F, Vernucci M, Ungaro P, Bruni CB, Riccio A (1999) Role of histone acetylation and DNA methylation in the maintenance of the imprinted expression of the $H 19$ and $I g f 2$ genes. FEBS Lett 458:45-50

Rainier S, Johnson LA, Dobry CJ, Ping AJ, Grundy PE, Feinberg AP (1993) Relaxation of imprinted genes in human cancer. Nature 362:747-749

Reik W, Walter J (2001) Genomic imprinting: parental influence on the genome. Nat Rev Genet 2:21-32

Ren B, Robert F, Wyrick JJ, Aparicio O, Jennings EG, Simon I, Zeitlinger J, Schreiber J, Hannett N, Kanin E, Volkert TL, Wilson CJ, Bell SP, Young RA (2000) Genome-wide location and function of DNA binding proteins. Science 290:2306-2309

Saitoh S, Wada T (2000) Parent-of-origin specific histone acetylation and reactivation of a key imprinted gene locus in Prader-Willi syndrome. Am J Hum Genet 66:1958-1962

Simon I, Tenzen T, Reubinoff BE, Hillman D, McCarrey JR, Cedar H (1999) Asynchronous replication of imprinted genes is established in the gametes and maintained during development. Nature 401:929_ 932

Strahl BD, Allis CD (2000) The language of covalent histone modifications. Nature 403:41-45

Wolffe AP, Matzke MA (1999) Epigenetics: regulation through repression. Science 286:481-486

Yoshida M, Kijima M, Akita M, Beppu T (1990) Potent and specific inhibition of mammalian histone deacetylase both in vivo and in vitro by trichostatin A. J Biol Chem 265:17174-17179 